\title{
An Alternative Approach for Analysis of Data from a Long-Term Experiment
}

\author{
T. S. G. PEIRIS \\ Coconut Research Institute, Lunuwila, Sri Lanka \\ and \\ E. K. SENEVIRATNE \\ Dept. of Statistics and Computer Science, \\ University of Colombo 3, Sri Lanka
}

\begin{abstract}
Long term experiments are commonly analysed at the end of the experiment using all the data collected over the entire duration of the experiment. Various methods are adopted to analyse such data but, in general, little consideration is given to the effect of climatic factors during this period. Consequently, information gathered from such an analysis is often incomplete.

An alternative approach for data analysis is proposed where the successive years of the experiment are classified into two states, namely, "Good year" and "Bad year" depending on the weather conditions. As a result, four different possible situations namely, "good year followed by a bad year", "good year followed by a good year", "bad year followed by a good year" and "bad year followed by a bad year" are considered. The method is illustrated using a data set from a trial carried out at the Coconut Research Institute and has demonstrated the feasibility of obtaining precise information on the treatment effect.
\end{abstract}

\section{INTRODUCTION}

A long-term experiment is one which is continued on the same set of plots over a number of years with a pre-planned sequence of treatments. Because of the cumulative character of the treatment effect and the cost involved in such experiments, more emphasis has to be given on analysing data from these experiments to obtain as much information as possible. The data collected over the life of the experiment are commonly analysed at the end of the experiment. Of the various methods available to analyse such data, only very few methods consider the time effect as a random variable.

One method used for some perennial crops is to divide the time taken by the experiment into two periods on the assumption that the perennials are biennial in cropping (Pearce, 1953). Another approach is to consider successive years as a separate variable and to include the "year effect" in the linear model used. Neither of these methods consider the direct effect of weather during the period of the experiment. 
As the variation of rainfall is generally considerable, it is very important to consider the distribution of rainfall throughout the year. This will provide more useful information to the experimenter. Further, though rainfall measurements are recorded daily at the experiment site (or at a place within the close range of the experiment site) these data have very seldom been used in formal analysis. Abeyasekara and Seneviratne (1983) highlighted the many inherent limitations in the use of monthly and yearly rainfall data.

This paper proposes a method for using daily rainfall in analysing data from long-term experiments. The successive years of the experiment are classified into two states namely, "Good year" and "Bad year" depending on the distribution of rainfall in the years. The risk of long dry spells, start of the rains and end of the rains in the two rainy seasons, Yala and Maha are used to classify years. The importance of these parameters to agriculture have been discussed by Stern et al. (1982a;1982b). A basis for classification of years is defined for coconut. However this definition can be adjusted for any crop, depending on its requirements. The total period of the experiment is broken into four groups depending on the state of the previous year and the current year. The analysis is then carried out separately for the four groups using a simple analysis of variance, without adding "year effect" into the model.

This method is illustrated using a data set from an irrigation experiment carried out at the Coconut Research Institute at Ratmalagara Estate in Puttalam district (Abeyawardena, 1979).

\section{Data Set}

The annual yield data from 1975-1984 of the 'medium' palms of the experiment were used. The experiment design was a fully randomized design with four treatments including the control. The data were analysed initially using a two-way Analysis of Variance (ANOVA) model considering years as blocks.

The daily rainfall for 30 years (1958-1987) at Ratmalagara was used to classify years being "Good" and "Bad". The date of the start of rains, end of rains and length of rainy period in both Yala and Maha seasons and the probabilities of long dry spells were calculated for each year. A threshold value of $0.5 \mathrm{~mm}$ was chosen and a day was classified as being wet if the amount of rain falling on that day was greater than or equal to the threshold value. If not, a day was classified as being dry. The data were then analysed separately for the four possible states without considering years as blocks.

\section{RESULTS AND DISCUSSION}

\section{(a) Approach without considering climatic effect}

The yield data were analysed using the two-way ANOVA model including the year effect as blocks. The ANOVA is given in the Table 1.

As can be seen, the treatments are statistically significant and there is high variation between years that could affect the treatments. This is mainly due to changes in weather between years. More details of this effect cannot be obtained because the effect of rainfall was not included directly in the analysis. Consequently, the information of the treatment effects gathered by the experimenter is often incomplete. From the above standard error it is clear that the three watering 
treatments are significant in comparison with the control and the treatment 1 is significant when compared with both treatments 2 and 3 , regardless of the climatic changes over the duration of the experiment.

Table 1. Two-way ANOVA

\begin{tabular}{lrrr}
\hline & $D F$ & $M S$ & F-Value \\
\hline Year & 9 & 401.98 & $17.21^{* * *}$ \\
Treatment & 3 & 529.38 & $22.66^{* * *}$ \\
Error & 27 & 23.36 & \\
Total & 39 & & \\
& & & \\
& & & \\
& Means: & Treatment 1 & 73.06 \\
& & Treatment 2 & 69.06 \\
& & Treatment 3 & 67.34 \\
& & Control & 56.00 \\
& & & \\
& & &
\end{tabular}

SE for difference between any two means $(16 \mathrm{df})=2.16$

*** Denotes values which achieved significance at $P<0.001$.

\section{(b) Analysis using the climatic effect}

The average annual rainfall at Ratmalagara Estate is around $1750 \mathrm{~mm}$ and the general rainfall pattern is bimodel with two peaks in Yala (April-June) and Maha (mid September to end November) seasons. As far as coconut is concerned, it is known that a good rainfall year is followed by a good crop year and poor rainfall year is followed by a poor crop year. The parameters for a good rainfall year for coconut are not known. An evenly distributed total rainfall of about $1500 \mathrm{~mm}$ in a year is favourable for coconut. Therefore in this preliminary study, the start, end and the length of rain in both Yala and Maha seasons have been used together with data on the risk of long dry spells between the periods from the end of Yala to the start of Maha and end of Maha to the start of Yala in order to categorise the years.

\section{(c) Start of the rains}

Defining an event like the start of rains or end of the rains is difficult, because of the intermittent and patchy nature of tropical rainfall. This definition is based solely on daily rainfall. Such an event could be defined in different ways for different crops. However, the rainfall requirement at different stages of the development cycle of coconut and the minimum dry period for the palm to exert moisture stress etc. are not known exactly.

In this study the date of the start of the rain in Yala season, in a given year, is defined as the earliest possible day after the 1st of April with more than $100 \mathrm{~mm}$ and less than $600 \mathrm{~mm}$ of rain totalled over 20 days. In addition at least 10 days should be rainy days and there should not be a dry spell of length $\mathbf{1 0}$ days or more in the next 20 days. A similar definition was used for the start of the rain in Maha season. The first day was replaced by the 15th of September.

The cumulative probability distributions of the start of the rains in Yala season and the start of the rains in Maha season at Ratmalagara Estate are shown in Fig. 1 and Fig. 2 respectively. Fig. 1 shows that the chance of rains commencing in Yala by the day number 123 (2nd May) and 153 (1st June) are 50\% and 75\% respectively. 


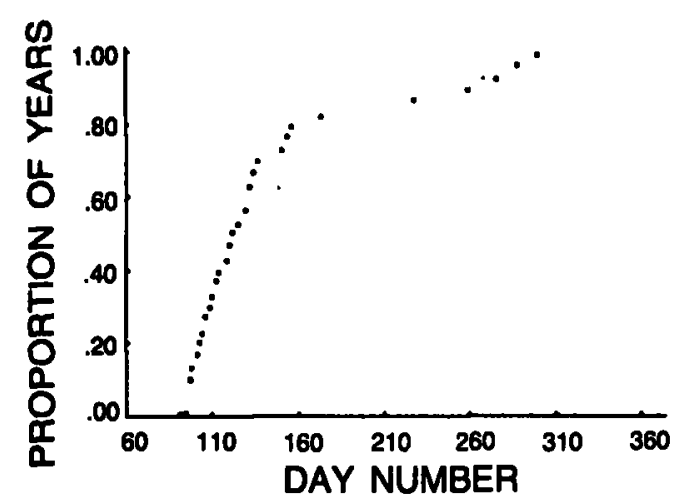

Fig 1: Cumulative Probability of the start of the rains in Yala at Ratmalagara Estate.

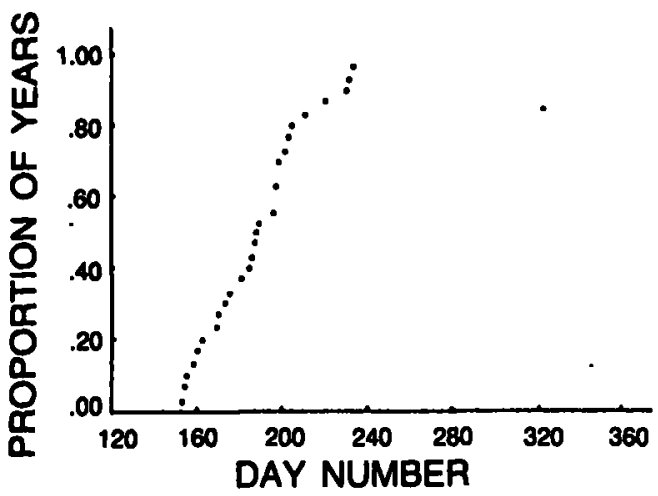

Fig 3: Cumulative Probability of the end of the rains in Yala at Ratmalagara Estate.

这

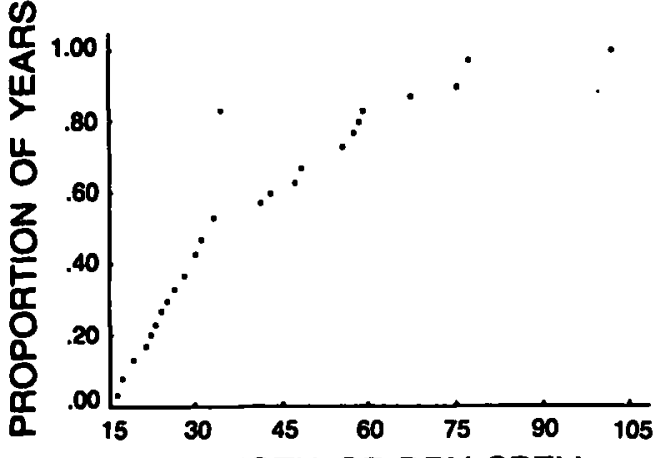

LENGTH OF DRY SPELL

Fig 5: Cumulative Probability of dry spells between and of Yala and start of Maha at Ratmalagara Estate.

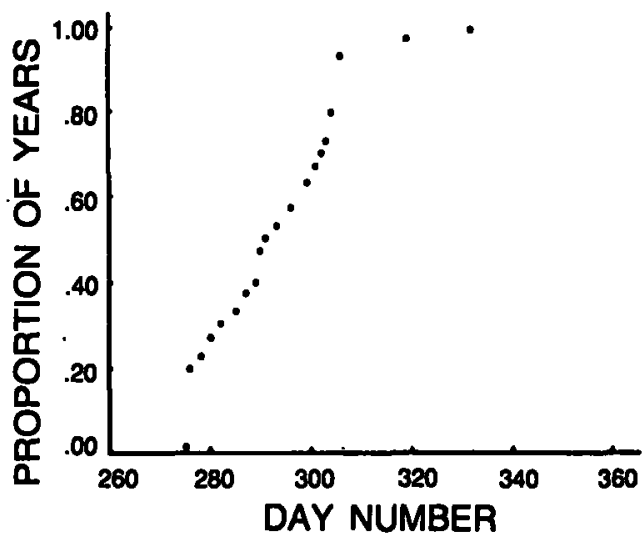

Fig 2: Cumulative Probability of the start of the rains in Maha at Ratmalagara Estate.

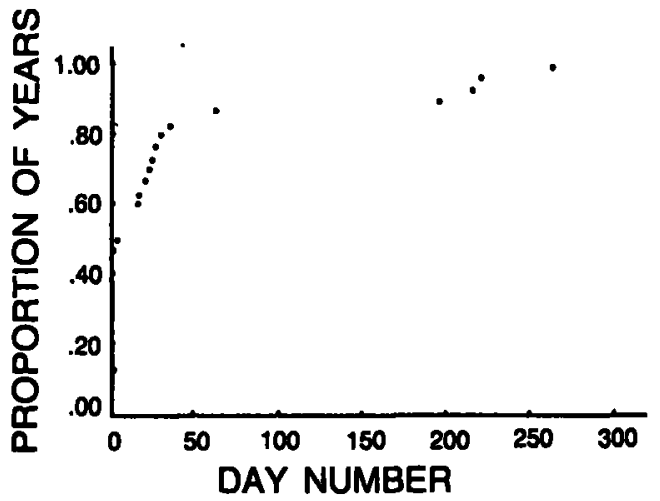

Fig 4: Cumulative Probability of the end of the rains in Maha at Ratmalagara Estate.

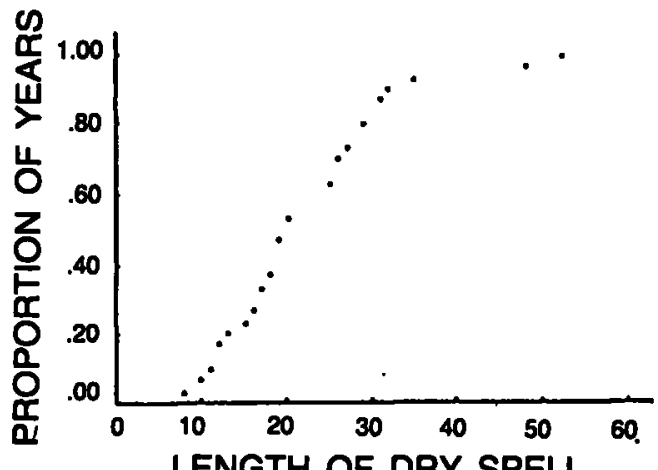

LENGTH OF DRY SPELL

Fig 6: Cumulative Probability of dry spells between end of Maha and start of Yala at Ratmalagara Estate. 
Similarly Fig. 2 shows that the chance of rains starting in Maha season by day number 292 (18th October) and 304 (30th October) are 50\% and 75\% respectively.

\section{(d) End of the rains}

The end of rains is also an important event for any crop which depends on the quantum of daily rainfall. The date for the end of the rain in Yala season was defined as the first day of at least 15 consecutive dry days after first of June. The end of the rains in Maha season was taken as the first day of at least 25 consecutive dry days after first of January. The cumulative probability distribution of the end of the rains in Yala season and the end of the rains Maha season at Ratmalagara Estate are shown in Fig. 3 and Fig. 4 respectively. Fig. 3 shows the chance of the end of the rains occurring in Yala season by day number 189 (7th July) and by day number 203 (23rd July) are $50 \%$ and $75 \%$ respectively. Fig. 4 shows that the $50 \%$ and $75 \%$ points for the Maha season are 9th January and 26th January respectively.

The years in which rains commence after the dates at which $50 \%$ of years had started rain and the rains end before the dates at which $50 \%$ of years had finished rain in both Yala and Maha seasons are classified as bad years since the length of the rainfall period is shorter than normal. Similarly, the years in which rains commence before the dates at which $50 \%$ of years had started rain and rains end after the dates at which $50 \%$ of years had finished rains in both seasons are classified as good years since the length of the rainfall period is longer than normal.

The length of the rainy period for each year was calculated by substracting the date at which the rain began from the date on which rain ended. It was also observed that the correlation between the dates of beginning and end of rain was very low and was not significant even at $10 \%$ level. Classification of years which do not fall into the above was done by judging the risk of dry spells.

\section{(e) Dry spells}

The occurrence of dry spells is another important variable that cannot be studied without access to the daily rainfall data. The maximum dry spell between the date at which $75 \%$ of years end rain for the Yala season and the date at which $75 \%$ of years start rain for the Maha season (say period, P1) were calculated for each year. Similarly, the maximum dry spells between the date at which $75 \%$ of the years finish rain for the Maha season and the date at which $75 \%$ of the years start rain for the Yala season (say period, P2) were also calculated for each year. The cumulative probability of. dry spells for the periods, P1 and P2 is shown in Fig. 5 and Fig. 6 respectively. It can be seen that $50 \%$ of years had dry spells of 20 days or more and 33 days or more in the periods $\mathrm{P} 1$ and $\mathrm{P} 2$ respectively. The dry spell of 20 days and 33 days therefore is considered as the critical value for those two dry periods.

Years were classified as good and bad with the combination of dry spells in two dry periods and start of the rains and the end of the rains in two rainy seasons. From the above critical values, the years 1975, 1976, 1977, 1978, 1984 and 1985 were good years and the years 1974, 1979, 1980, 1981, 1982 and 1983 were bad years. Only the years between 1974 and 1985 were classified because the experiment had been conducted from 1975 to 1984 . As a result of the above classification, the years 1976, 1977 and 1978 belonged to the group of good years followed by good years and the year 1979 belonged to the group of bad years followed by good years. These two groups were denoted by $G / G$ abd B/G respectively. Similarly the years where bad 
year followed by a bad year were 1980, 1981, 1982 and 1983 and the years where good year followed by a bad year were 1975 and 1984. These two groups were denoted by $B / B$ and $G / B$ respectively. The analyses were then carried out separately for the above four groups, $G / G, B / G, B / B$ and $G / B$. The mean sum of squares(MS) of these four groups along with means are given in the Table 2.

Table 2. Summary of ANOVAs.

$M S$

\begin{tabular}{lccccc}
\hline Source & $D F$ & $G / G$ & $B / G$ & $B / B$ & $G / B$ \\
\hline Treatments & 3 & 68.07 & $412.41^{* * *}$ & $343.68^{*}$ & $251.38^{* *}$ \\
Error & 16 & 93.93 & 34.54 & 83.23 & 41.02 \\
Total & 19 & & & & \\
& & & & & \\
Means: & & 77.20 & 79.60 & 69.65 & 72.53 \\
Treatment 1 & & 75.20 & 74.50 & 62.90 & 71.33 \\
Treatment 2 & & 73.00 & 71.10 & 62.60 & 70.33 \\
Treatment 3 & 68.60 & 58.30 & 49.80 & 57.33 \\
Control & & & & \\
SE for difference between any two & & & & \\
means (16 df) & 6.10 & 3.72 & 5.77 & 4.05 \\
\hline
\end{tabular}

",** and *** denote values which achieved significance at $P<0.05,0.01$ and 0.001 respectively.

From the Anova for $G / G$, it is seen that when both the previous year and the current year are good rainfall years the treatments were not significant. In all other three situations, the three irrigation treatments were significant compared to the control. Further, when a bad rainfall year followed by a good rainfall year (B/G), the treatment 1 is significantly different from treatment 3 . Treatment 1 also gave the highest yield. When the previous year had bad rainfall, irrespective of the current year's rainfall, all three treatments were not statistically significant. This shows that the above results give more useful information of the treatment effects to the experimenter than the results obtained in the Section (a), when different situations of climatic groups were considered.

\section{CONCLUSION}

The data presented illustrate the benefits of using daily rainfall variation in the analysis of data from a long-term experiment in perennial crop. This approach is very useful in obtaining valuable agronomic information on the treatment effects of the experiment. It is easy to apply and flexible as the parameters used for classification of years can be modified to suit any crop. This approach works well in this particular example because of irrigation treatments. However it would apply equally well to other long-term experiments.

By applying this method to data of a randomized block design experiment, additional information of agronomic importance can be obtained and the use of complex analyses, such as split-plot or multivariate models in order to consider the year-effect can be avoided. These analyses have many statistical limitations. 


\section{T. S. G. PEIRIS and E. K. SENEVIRATNE}

If the entire duration of the experiment cannot be grouped into the four possible states, the analyses can be carried out for the two groups namely, good years and bad years separately. Though the method of classification of years is a subjective one, it can be improved by using other climatic factors which affect the crop. This method paves the way for assessing the relationship between climatic factors and the yield.

\section{ACKNOWLEDGEMENT}

The authors are grateful to the referee for the valuable comments and suggestions for improving the paper and to Dr. R. Mahindapala, Director, CRI, for his comments on the manuscript. Our thanks are also due to Mr. D. T. Mathes, Senior Biometrician, CRI, for his suggestions and the staff of the Biometry Unit for their kind assistance.

\section{REFERENCES}

Abeyasekare, Savitri \& E. K. Seneviratne (1983). The analysis of daily rainfall data for agricultural purposes. J. Nat. Sci. Coun. Sri Lanka, 11(2) 165-183.

Abeyawardena, V. (1979). Influence of watering on the yield of coconut. Ceylon Coconut $Q ., 30,90-100$.

Pearce, S. C. (1953). Field experimentation with fruit trees and other perennial plants. $70 \mathrm{pp}$, 1st ed. Commonwealth Agricultural Bureaux, Farnham Royal, England

Stern, R. D., M. D. Dennett, \& I. C. Dale (1982 a). Analysing daily rainfall measurements to give agronomically useful results. I. Direct method. Expl. Agric., 18, 223-236.

Stern, R. D., M. D. Dennett, \& I. C. Dale, (1982 b). Analysing daily rainfall measurements to give agronomically useful results. II. A Modelling approach. Expl. Agric., 18, 237-253. 